\title{
MiR-139-5p is Increased in the Peripheral Blood of Patients with Prostate Cancer
}

\author{
Cheng Panga,b Ming Liu ${ }^{\mathrm{b}}$ Weiwei Fanga,c Jun Guo ${ }^{\mathrm{a}}$ Zhipeng Zhang ${ }^{\mathrm{b}}$ Pengjie Wu $\mathrm{W}^{\mathrm{b}}$ \\ Yaoguang Zhang ${ }^{b}$ Jianye Wang ${ }^{a, b}$
}

aGraduate School of Peking Union Medical College and Chinese Academy of Medical Sciences, ${ }^{\mathrm{b} B e i j i n g ~ H o s p i t a l, ~ N a t i o n a l ~ C e n t e r ~ o f ~ G e r o n t o l o g y, ~ ' T h e ~ K e y ~ L a b o r a t o r y ~ o f ~ G e r i a t r i c s, ~ B e i j i n g ~ I n s t i t u t e ~ o f ~}$ Geriatrics and Beijing Hospital, Ministry of Health, Beijing, China

\section{Key Words}

MiR-139-5p - Prostate cancer $\cdot$ Benign prostatic hyperplasia $\cdot$ Biomarker Peripheral whole blood

\begin{abstract}
Background: Emerging evidence suggested that microRNAs (miRNAs) play a causal role in cancer tumorigenesis. Aberrant expression of miRNA (miR)-139-5p has been observed in various types of cancers. The present study evaluated the relationship between miR-139$5 p$ expression levels and prostate cancer (PCa), to assess the feasibility of using peripheral blood miR-139-5p as a potential non-invasive biomarker for PCa. Methods: Total RNA was extracted from peripheral whole blood samples from 45 PCa patients, 45 benign prostatic hyperplasia (BPH) patients and 50 healthy controls $(\mathrm{HC})$. The expression of miR-139-5p was assessed by reverse transcription quantitative polymerase chain reaction. Results: MiR-139$5 p$ in peripheral blood was significantly higher in PCa patients than in patients with $\mathrm{BPH}$ and $\mathrm{HC}$ individuals $(\mathrm{P}<0.001)$. Higher miR-139-5p expression was observed to be associated with certain clinicopathological parameters, including $P S A>20 \mathrm{ng} / \mathrm{ml}(P<0.05)$, pathological tumor stage 3/4 $(P<0.05)$ and Gleason score $>7(P<0.01)$. A receiver operating characteristic $(R O C)$ curve analysis revealed that miR-139-5p distinguished $\mathrm{PCa}$ patients from BPH patients [area under the curve (AUC), 0.936; 95\% CI, 0.878-0.993; $\mathrm{P}<0.001]$. Conclusions: Peripheral blood miR-139-5p may be utilized as a potential novel non-invasive biomarker for PCa screening.
\end{abstract}

(C) 2016 The Author(s)

Published by S. Karger AG, Basel

\section{Introduction}

PCa is the most commonly diagnosed malignant tumor in male and the second leading cause of cancer-associated deaths in western countries, with increasing mortality and incidence rates [1]. Currently, serum prostate-specific antigen (PSA) is the standard diagnostic biomarker for $\mathrm{PCa}$, which exhibits increased levels in patients with PCa. According 


\section{Cellular Physiology Cell Physiol Biochem 2016;39:1111-1117 \begin{tabular}{l|l|l|} 
and BOI: 10.1159/000447819 & $\begin{array}{l}\text { C) 2016 The Author(s). Published by S. Karger AG, Basel } \\
\text { www.karger.com/cpb }\end{array}$
\end{tabular} \\ Pang et al.: miR-139-5p is a Potential Biomarker for Prostate Cancer}

to the different level of serum PSA (PSA $<10 \mathrm{ng} / \mathrm{ml}$, PSA10-20ng $/ \mathrm{ml}$ and PSA $>20 \mathrm{ng} / \mathrm{ml}$ ), combined with tumor stage and Gleason score, PCa can be divided into three different risk groups (low-risk, intermediate-risk and high-risk) [2]. However, the level of serum PSA could be increased in various diseases, including trauma, prostatitis and BPH [3], which usually leads to overdiagnosis and overtreatment [4]. Furthermore, the PSA measurement is insufficient to identify clinical insignificant PCa. Urinary prostate cancer antigen 3 (PCA3) has been used as a non-invasive diagnostic biomarker for PCa screening, and the nomograms base on clinical parameters is also helpful, but it is not sufficient to distinguish PCa patients from healthy individuals [5-7].Therefore, it is urgent to develop more effective non-invasive biomarkers for screening the populations at risk.

MiRNAs belong to a class of highly conserved short non-coding RNAs, which regulate gene expression by binding to the 3' untranslated region (3' UTR) of target messenger RNAs (mRNAs) $[8,9]$. MiRNAs play crucial roles in various cellular functions, including cell differentiation, proliferation and apoptosis [10]. Several evidences suggest that aberrant expression of miRNAs contributes to tumor proliferation, apoptosis, metastasis, invasion and anti-tumor drug resistance [11-13]. A variety of miRNAs have been found to be dysregulated in PCa $[5,6,14]$. Moltzahn et al found that miR-93, miR-106a and miR-24 were higher in the patients with early stage PCa immediately before prostatectomy than the healthy males [15]. According to Bryant et al, 12 miRNAs were altered in the circulation system of 78 patients with PCa compared with 28 healthy males, and miR-107 was one of the greatest changed biomarkers in this study [16].

In particular, miR-139-5p is one of the most common cancer-associated miRNAs, which has been reported as tumor suppressor in several malignancies, such as breast cancer [17], colorectal carcinoma [18], hepatocellular carcinoma [19], parathyroid carcinoma [20], and so on. On the contrary, overexpression of $m i R-139-5 p$ has been recently correlated with granulose cells and bladder carcinoma [21]. However, the expression of miR-139-5p in PCa remains unclear.

Therefore, the present study aims to evaluate the expression of $m i R-139-5 p$ in the peripheral whole blood of PCa, BPH patients, and in healthy males, thereby investigating the potential use of blood miR-139-5p as a non-invasive PCa diagnostic biomarker.

\section{Materials and Methods}

\section{Patients and blood samples}

All peripheral whole blood samples of PCa, BPH patients, and healthy individuals were obtained from the Department of Urology, Beijing Hospital (Beijing, China) between June 2014 and January 2016. The application of patient-derived materials was approved by the Research Ethics Committee of Beijing Hospital, and written consent was obtained from all patients. No patients received androgen deprivation therapy or radiotherapy. The characteristics of the patients were shown in Table1.

Table1. Characteristics of participants

\begin{tabular}{lccc}
\hline Variable & Prostate cancer & Benign prostatic hyperplasia & Healthy controls \\
\hline Total subjects; n & 45 & 45 & 50 \\
Age, years; mean (range) & $70(55-83)$ & $69(55-81)$ & $70(56-81)$ \\
BMI, kg/m² & $24.4 \pm 2.81$ & $24.1 \pm 3.34$ & $25.5 \pm 2.38$ \\
PSA, ng/ml; n (\%) & & & \\
$<10$ & $21(46.7)$ & $45(100.0)$ & $50(100.0)$ \\
$10-20$ & $7(15.6)$ & $0(0)$ & $0(0)$ \\
$>20$ & $17(37.7)$ & $0(0)$ & $0(0)$ \\
Gleason score; n (\%) & & - & - \\
$<7$ (low) & $10(22.2)$ & - & - \\
7 (intermediate) & $26(57.8)$ & - & - \\
$>7$ (high) & $9(20.0)$ & - & - \\
Tumor stage; n (\%) & & - & - \\
pT1/2 & $29(64.4)$ & - & \\
pT3/4 & $16(35.6)$ & & \\
\hline
\end{tabular}




\section{Cellular Physiology Cell Physiol Biochem 2016;39:1111-1117 \begin{tabular}{l|l} 
and Biochemistry & DOI: 10.1159/000447819 \\
Published 2016 The Author(s). Published by S. Karger AG, Basel \\
www.karger.com/cpb
\end{tabular} \\ Pang et al.: miR-139-5p is a Potential Biomarker for Prostate Cancer}

RNA extraction

The total RNA from the whole blood samples $(5 \mathrm{ml})$ collected in tubes containing EDTA was extracted with RNAVzol LS (Vigorous Biotechnology, Beijing) rigorously according to the manufacturer's instructions. The concentration and the purity of the RNA samples were assayed by absorbent density analysis on $\mathrm{OD}_{260} / \mathrm{OD}_{280^{\circ}}$

Reverse transcription (RT) and quantitative (q) polymerase chain reaction (PCR)

For synthesis of cDNA of the specific miR, $1 \mu \mathrm{g}$ of the total RNA was reversely transcribed using TaqMan MicroRNA Reverse Transcription Kit (Applied Biosystems) with specific primers for miR-139-5p and U6 (Shanghai Sangon Technology).To quantify the miR-139-5p, a quantitative real-time PCR assay was performed using SYBR Green Supermix (Bio-Rad) in a BIO-RAD iCycleriQ real-time PCR detection system. The PCR amplifications were performed in a $10 \mu \mathrm{l}$ reaction system containing $5 \mu \mathrm{l}$ SYBR Green Supermix, $0.4 \mu \mathrm{l}$ forward primer $(10 \mathrm{nM}), 0.4 \mu \mathrm{l}$ reverse primer $(10 \mathrm{nM}), 2.2 \mu \mathrm{l} \mathrm{ddH} 2 \mathrm{O}$ and $2 \mu \mathrm{l}$ template cDNA. The thermal cycling conditions were a hot start step at $95^{\circ} \mathrm{C}$ for $10 \mathrm{~min}$, followed by 40 cycles at $95^{\circ} \mathrm{C}$ for 15 $\mathrm{s}$ and $60^{\circ} \mathrm{C}$ for $1 \mathrm{~min}$. The relative level of miR-139-5p was determined using the 2-delta delta Ct analysis method. We choose U6 as the endogenous control. Nucleotide primers used for reverse transcription were as follows (5'-3'): miR-139-5p, CGT ATC CAG TGC AGG GTC CGA GGT ATT CGC ACT GGA TAC GAC ACT GGA; U6, TCG TAT CCA GTG CAG GGT CCG AGG TAT TCG CAC TGG ATA CGA CAA ATAT G.

The primers used for real-time PCR were as follows (5'-3'): miR-139-5p forward, GCT CTA CAG TGC ACG TGT C; U6 forward, GCG TCG TGA AGC GTT C; Universal reverse primer, GTG CAG GGT CCG AGG T.

\section{Statistical analysis}

Data are presented as mean \pm SD. Differences were carried out with Student's t test. ROC curves were used to assess miR-139-5p as a biomarker, and the AUC was reported. $\mathrm{P}<0.05$ was considered as statistically significant difference.

\section{Results}

\section{Patients characteristics}

The demographics and clinical characteristics of the HC, BPH patients and PCa patients were outlined in Table1. The age distribution was similar in the three groups $(\mathrm{P}>0.05)$. Serum PSA levels were significantly higher in PCa patients compared with that in BPH patients and HC individuals $(\mathrm{P}<0.001)$.

Elevated expression of miR-139-5p in peripheral blood of PCa patients compared with $B P H$ patients and healthy individuals

The level of miR-139-5p was examined in the peripheral blood of PCa, BPH patients and HC subjects using real-time PCR. The expression of miR-139-5p was significantly upregulated in the peripheral blood of patients with PCa compared with that of BPH patients

Fig. 1. Elevated expression of $m i R-139-5 p$ in peripheral blood of prostate cancer (PCa) patients compared with benign prostate hyperplasia (BPH) patients and healthy individuals(healthy controls,HC). The levels of $m i R-139-5 p$ was measured in peripheral blood samples from PC patients $(n=45)$, BPH patients $(n=45)$ and healthy control individuals $(n=50)$. Data represent the mean \pm S.D. ${ }^{*} \mathrm{p}<0.05$; $^{* *} \mathrm{p}<0.01$; $^{* *} \mathrm{p}<0.001$ (vs. $\mathrm{BPH}$ patients and controls).

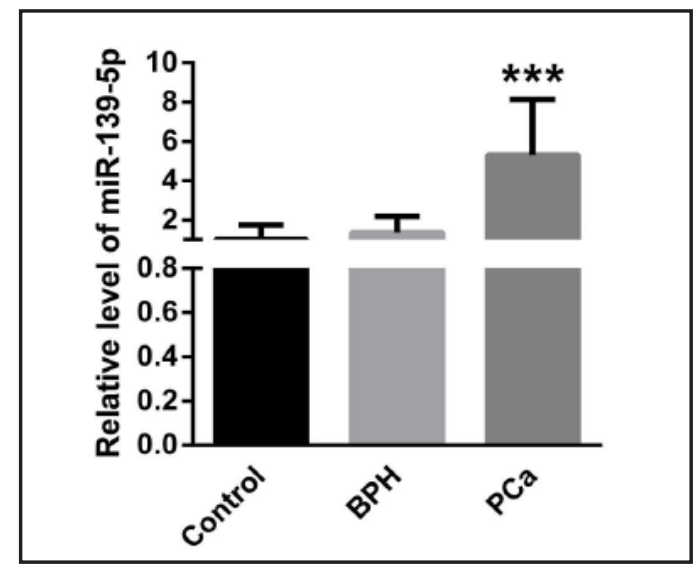


A

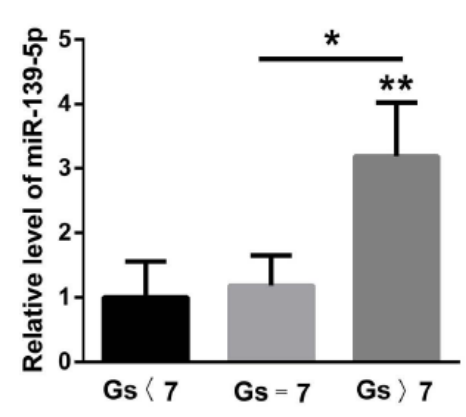

B

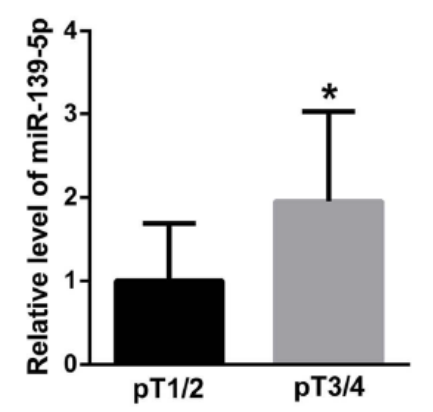

C

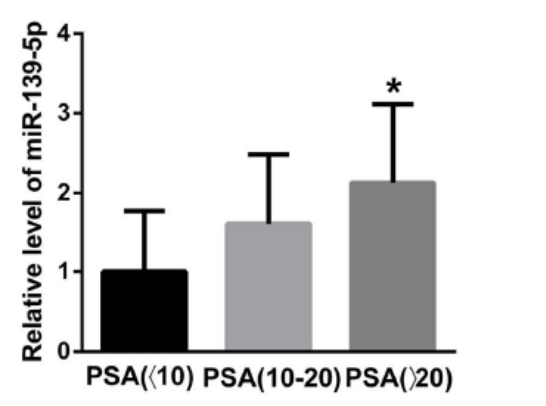

Fig. 2. Clinicopathological parameters changes are accompanied by up-regulation of miR-139-5p in peripheral blood of PCa patients. (A) Relative expression levels of miR-139-5p in patients with $\mathrm{Gs}<7, \mathrm{Gs}=7$ and Gs $>7\left({ }^{*} \mathrm{P}<0.05\right.$ vs. Gs $<7 ;{ }^{* *} \mathrm{p}<0.01$ vs. Gs=7). (B) Relative miR-139-5p expression in patients of stage pT1/2 and pT3/4 ( ${ }^{*} \mathrm{P}<0.05$ vs. pT1/2). (C) The levels of miR-139-5p in patients with $\mathrm{PSA}<10, \mathrm{PSA}=10-20$ and $\mathrm{PSA}>20$ ( ${ }^{*} \mathrm{P}<0.05$ vs. $P S A<10)$. Data are presented as the mean \pm S.D. Gs, Gleason score; pT, pathological tumor stage; PSA, prostate-specific antigen.
A

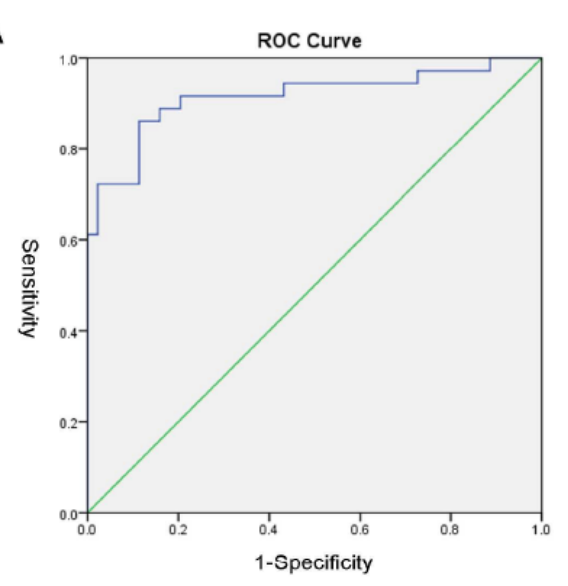

B

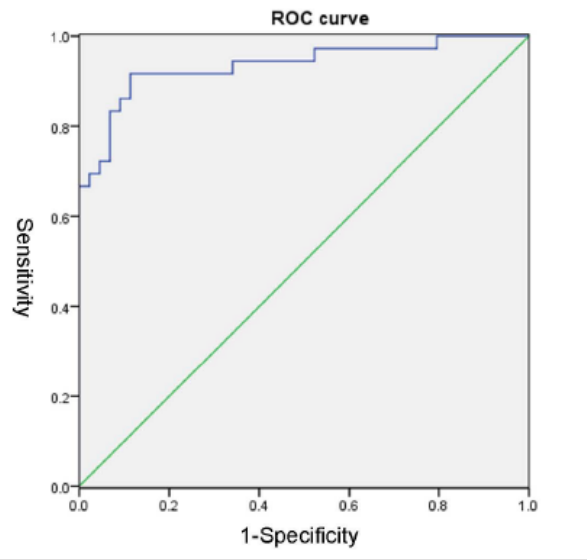

Fig. 3. ROC curve analysis. (A) miR-139-5p can distinguish $\mathrm{PCa}$ patients from healthy controls (AUC, 0.915; 95\% CI, 0.846-0.984; $\mathrm{P}<0.001$ ). (B) The expression change of $m i R-139-5 p$ can distinguish PCa patients from BPH patients (AUC, 0.936; 95\% CI, 0.878-0.993; $\mathrm{P}<0.001)$. ROC, receiver operating characteristic; AUC, area under the curve; CI, confidence interval.

and $\mathrm{HC}$ individuals $(\mathrm{P}<0.001)$ (Fig. 1$)$. The relative expression of $m i R-139-5 p$ was $5.3 \pm 2.8$ for PCa patients, $1.4 \pm 0.8$ for BPH patients and $1 \pm 0.8$ for healthy controls.

Clinicopathological parameters changes are accompanied by up-regulation of miR-139$5 p$ in peripheral blood of prostate cancer patients

PCa patients with more aggressive tumors exhibited significantly higher miR-139-5p expression compared with that of patients with less aggressive tumors. The mean relative $m i R-139-5 p$ level in the group of patients with a Gleason score $<7$ was $1 \pm 0.5$, and increased 


\section{Cellular Physiology Cell Physiol Biochem 2016;39:1111-1117

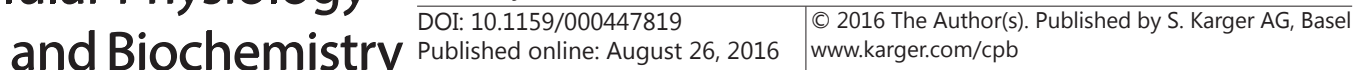 \\ Pang et al.: miR-139-5p is a Potential Biomarker for Prostate Cancer}

progressively to $1.6 \pm 0.8$ in patients with a Gleason score of 7, and to $2.2 \pm 1.1$ in patients with a Gleason score $>7$ (Fig. 2A). In addition, miR-139-5p expression was significantly higher in patients at an advanced stage of disease: Patients with a pathological tumor (pT) stage of 3 or 4 exhibited a mean relative $m i R-139-5 p$ expression level of $1.9 \pm 1.0$, which was significantly increased compared with patients of pT stage 1 or $2(1.0 \pm 0.7)(\mathrm{P}<0.05)$ (Fig. 2B). The levels of $m i R-139-5 p$ in patients with $\mathrm{PSA}<10, \mathrm{PSA}=10-20$ and $\mathrm{PSA}>20$ was respectively $1 \pm 0.8$, $1.6 \pm 0.9$ and $2.1 \pm 1.0$ (Fig. 2 C).

The expression of miR-139-5p may be regarded as a potential diagnostic tool

As miR-139-5p was differentially expressed in the peripheral blood of PCa patients, BPH patients and HC, peripheral blood miR-139-5p might be a promising marker. Based on an ROC analysis, blood miR-139-5p was able to distinguish PCa patients from healthy controls (AUC, 0.915; 95\% CI, 0.846-0.984; $\mathrm{P}<0.001$; Fig. 3A), suggesting miR-139-5p can distinguish PCa patients from BPH patients (AUC, 0.936; 95\% CI, 0.878-0.993; $\mathrm{P}<0.001$; Fig. 3B).

\section{Discussion}

PCa is the most commonly diagnosed malignance in male. The main parameters for PCa diagnosis are PSA testing, digital rectal examination (DRE), PCA3, multiparametric magnetic resonance image (mpMRI) and Gleason score [5]. However, the diagnostic tools are relatively limited. MiRNAs belong to a type of small non-coding RNAs that are widely involved in both physiological and pathological condition [22-24]. For instance, miR-125b [25] and miR-449a [26] are respectively involved in the physiological condition of apoptosis and autophagy. At the same time, miR-135a [27] and $m i R-21$ [28] are respectively involved in the pathological process of tumor and insulin resistance. It has been widely acknowledged that any disruption of miRNAs may cause dysregulation in cellular homeostasis and further lead to oncogenesis [29]. Therefore, the investigation of miRNAs may shed light on the understanding of PCa progression and be helpful to identify potential biomarkers.

$M i R-139-5 p$ is one of the most important miRNAs that has been shown to be dysregulated in a variety of cancers, including breast cancer, gastric cancer [30,31]. In the current study, we firstly explored the expression of $m i R-139-5 p$ in peripheral blood and determined that it was significantly higher in PCa patients than in patients with BPH and HC individuals, which showed a strong association between PCa and miR-139-5p expression. More importantly, the more high-risk stage, the higher expression of the miR-139-5 $p$ was found. Much higher expression of peripheral blood miR-139-5 $p$ was detected in PCa patients with more advanced stage (pT3/4) and more aggressive tumors (Gleason score $>7$ ), suggesting that peripheral blood miR-139-5p may be tightly associated with progression of PCa. In addition, the ROC analysis revealed that peripheral blood $m i R-139-5 p$ was able to distinguish patients with PCa from $\mathrm{BPH}$ patients and $\mathrm{HC}$, respectively.

Collectively, these results suggested a role for miR-139-5p in the pathogenesis of $\mathrm{PCa}$, and indicated $m i R-139-5 p$ as a non-invasive biomarker with high specificity and sensitivity for PCa detection.

Previous studies have shown that miR-139-5p can act as either tumor oncogenes or suppressors in several types of cancers. Yamashita et al observed that miR-139-5p can decrease tumor growth by inhibit the expression of HER2 in gastric cancer cell lines [32]. Xu et al exhibited that miR-139-5p functioned as a tumor suppressor by targeting insulin-like growth factor 1 receptor in human non-small cell lung cancer [33]. Zhang et al found that miR-139-5p inhibited the viability, invasion and migration of breast cancer cells by targeting notch1 [34]. The function of a given miRNA is determined by the relative availability of the downstream target mRNAs, as such the same miRNA could have a dual role in different tissues, specifically cancers of different cellular origin [35]. MiRNAs have been shown to function as either tumor suppressors or oncogenes depending on the cell or cancer type in which they are expressed. For example, miR-155 may function as a tumor suppressor in 


\section{Cellular Physiology Cell Physiol Biochem 2016;39:1111-1117 \begin{tabular}{l|l|l|} 
and BOI: 10.1159/000447819 & $\begin{array}{l}\text { C) 2016 The Author(s). Published by S. Karger AG, Basel } \\
\text { www.karger.com/cpb }\end{array}$
\end{tabular} \\ Pang et al.: miR-139-5p is a Potential Biomarker for Prostate Cancer}

pancreatic cancers [36], while in B-cell lymphomas it has oncogenic activity [37]. Another example of this is miR-125b, which has been shown to be a tumor suppressor in breast and ovarian cancer and to be a tumor oncogene in PCa [38]. So this situation is not unique to miR-139-5p.

In conclusion, the present study has a limited number of experimental samples, which may restrict the statistical power of the study. Therefore, several large prospective studies are required to confirm the role of $m i R-139-5 p$ in PCa. Despite this disadvantage, this study provides a novel potential non-invasive biomarker for PCa detection.

\section{Disclosure Statement}

The authors declared no conflict of interest.

\section{References}

1 Siegel RL, Miller KD, Jemal A: Cancer statistics, 2015. CA Cancer J Clin 2015;65:5-29.

2 Cooperberg MR, Pasta DJ, Elkin EP, Litwin MS, Latini DM, Du Chane J, Carroll PR: The University of California, San Francisco Cancer of the Prostate Risk Assessment score: a straightforward and reliable preoperative predictor of disease recurrence after radical prostatectomy. J Urol 2005;173:1938-1942.

3 Nadler RB, Humphrey PA, Smith DS, Catalona WJ, Ratliff TL: Effect of inflammation and benign prostatic hyperplasia on elevated serum prostate specific antigen levels. J Urol 1995;154:407-413.

4 Draisma G, Etzioni R, Tsodikov A, Mariotto A, Wever E, Gulati R, Feuer E, de Koning H: Lead time and overdiagnosis in prostate-specific antigen screening: importance of methods and context. J Natl Cancer Inst 2009;101:374-383.

5 Bertoli G, Cava C, Castiglioni I: MicroRNAs as Biomarkers for Diagnosis, Prognosis and Theranostics in Prostate Cancer. Int J Mol Sci 2016;17.

6 Jackson BL, Grabowska A, Ratan HL: MicroRNA in prostate cancer: functional importance and potential as circulating biomarkers. BMC cancer 2014;14:930.

7 Roobol MJ, Schroder FH, van Leeuwen P, Wolters T, van den Bergh RC, van Leenders GJ, Hessels D: Performance of the prostate cancer antigen 3 (PCA3) gene and prostate-specific antigen in prescreened men: exploring the value of PCA3 for a first-line diagnostic test. Eur Urol 2010;58:475-481.

8 Chan LS, Yue PY, Wong YY, Wong RN: MicroRNA-15b contributes to ginsenoside-Rg1-induced angiogenesis through increased expression of VEGFR-2. Biochem Pharmacol 2013;86:392-400.

9 Bao L, Hazari S, Mehra S, Kaushal D, Moroz K, Dash S: Increased expression of P-glycoprotein and doxorubicin chemoresistance of metastatic breast cancer is regulated by miR-298. Am J Pathol 2012;180:2490-2503.

10 Bartel DP: MicroRNAs: target recognition and regulatory functions. Cell 2009;136:215-233.

11 Wang H, Tan G, Dong L, Cheng L, Li K, Wang Z, Luo H: Circulating MiR-125b as a marker predicting chemoresistance in breast cancer. PloS one 2012;7:e34210.

12 Liang Z, Li Y, Huang K, Wagar N, Shim H: Regulation of miR-19 to breast cancer chemoresistance through targeting PTEN. Pharm Res 2011;28:3091-3100.

13 Zhao S, Han J, Zheng L, Yang Z, Zhao L, Lv Y: MicroRNA-203 Regulates Growth and Metastasis of Breast Cancer. Cell Physiol Biochem 2015;37:35-42.

14 Gao Q Yao X, Zheng J: MiR-323 Inhibits Prostate Cancer Vascularization Through Adiponectin Receptor. Cell Physiol Biochem 2015;36:1491-1498.

15 Moltzahn F, Olshen AB, Baehner L, Peek A, Fong L, Stoppler H, Simko J, Hilton JF, Carroll P, Blelloch R: Microfluidic-based multiplex qRT-PCR identifies diagnostic and prognostic microRNA signatures in the sera of prostate cancer patients. Cancer Res 2011;71:550-560.

16 Bryant RJ, Pawlowski T, Catto JW, Marsden G, Vessella RL, Rhees B, Kuslich C, Visakorpi T, Hamdy FC: Changes in circulating microRNA levels associated with prostate cancer. Br J Cancer 2012;106:768-774.

17 Rask L, Balslev E, Sokilde R, Hogdall E, Flyger H, Eriksen J, Litman T: Differential expression of miR-139, miR-486 and miR-21 in breast cancer patients sub-classified according to lymph node status. Cell Oncol 2014;37:215-227. 


\section{Cellular Physiology Cell Physiol Biochem 2016;39:1111-1117 \begin{tabular}{l|l|l|}
\hline DOI: 10.1159/000447819 & $\begin{array}{l}\text { C) } 2016 \text { The Author(s). Published by S. Karger AG, Basel } \\
\text { www.karger.com/cpb }\end{array}$
\end{tabular} \\ Pang et al.: miR-139-5p is a Potential Biomarker for Prostate Cancer}

18 Zhang L, Dong Y, Zhu N, Tsoi H, Zhao Z, Wu CW, Wang K, Zheng S, Ng SS, Chan FK, Sung JJ, Yu J: microRNA139-5p exerts tumor suppressor function by targeting NOTCH1 in colorectal cancer. Mol Cancer 2014;13:124.

19 Wong CC, Wong CM, Tung EK, Au SL, Lee JM, Poon RT, Man K, Ng IO: The microRNA miR-139 suppresses metastasis and progression of hepatocellular carcinoma by down-regulating Rho-kinase 2 . Gastroenterology 2011;140:322-331.

20 Corbetta S, Vaira V, Guarnieri V, Scillitani A, Eller-Vainicher C, Ferrero S, Vicentini L, Chiodini I, Bisceglia M, Beck-Peccoz P, Bosari S, Spada A: Differential expression of microRNAs in human parathyroid carcinomas compared with normal parathyroid tissue. Endocr Relat Cancer 2010;17:135-146.

21 Zhao G, Zhou X, Fang T, Hou Y, Hu Y: Hyaluronic acid promotes the expression of progesterone receptor membrane component 1 via epigenetic silencing of miR-139-5p in human and rat granulosa cells. Biol Reprod 2014;91:116.

22 Kloosterman WP, Plasterk RH: The diverse functions of microRNAs in animal development and disease. Dev Cell 2006;11:441-450.

23 Ha TY: MicroRNAs in Human Diseases: From Cancer to Cardiovascular Disease. Immune Netw 2011;11:135-154.

24 Baranwal S, Alahari SK: miRNA control of tumor cell invasion and metastasis. Int J Cancer 2010;126:12831290.

25 Yu G, Zhan X, Zhang Z, Li Y: Overexpression of miR-125b promotes apoptosis of macrophages. Xi Bao Yu Fen Zi Mian Yi Xue Za Zhi 2016;32:958-962.

26 Han R, Ji X, Rong R, Li Y, Yao W, Yuan J, Wu Q, Yang J, Yan W, Han L, Zhu B, Ni C: MiR-449a regulates autophagy to inhibit silica-induced pulmonary fibrosis through targeting Bcl2. J Mol Med (Berl) DOI:10.1007/s00109-016-1441-0.

27 Zhang C, Chen X, Chen X, Wang X, Ji A, Jiang L, Sang F, Li F: miR-135a acts as a tumor suppressor in gastric cancer in part by targeting KIFC1. Onco Targets Ther 2016;9:3555-3563.

28 Zhao XY, Shao K: Roles of MicroRNA-21 in the Pathogenesis of Insulin Resistance and Diabetic Mellitusinduced Non-alcoholic Fatty Liver Disease. Zhongguo Yi Xue Ke Xue Yuan Xue Bao 2016;38:144-149.

29 Bouyssou JM, Manier S, Huynh D, Issa S, Roccaro AM, Ghobrial IM: Regulation of microRNAs in cancer metastasis. Biochim Biophys Acta 2014;1845:255-265.

30 Guo J, Miao Y, Xiao B, Huan R, Jiang Z, Meng D, Wang Y: Differential expression of microRNA species in human gastric cancer versus non-tumorous tissues. J Gastroenterol Hepatol 2009;24:652-657.

31 Krishnan K, Steptoe AL, Martin HC, Pattabiraman DR, Nones K, Waddell N, Mariasegaram M, Simpson PT, Lakhani SR, Vlassov A, Grimmond SM, Cloonan N: miR-139-5p is a regulator of metastatic pathways in breast cancer. Rna 2013;19:1767-1780.

32 Yamashita H, Nishio M, Toyama T, Sugiura H, Zhang Z, Kobayashi S, Iwase H: Coexistence of HER2 overexpression and p53 protein accumulation is a strong prognostic molecular marker in breast cancer. Breast Cancer Res 2004;6:R24-30.

33 Xu W, Hang M, Yuan CY, Wu FL, Chen SB, Xue K: MicroRNA-139-5p inhibits cell proliferation and invasion by targeting insulin-like growth factor 1 receptor in human non-small cell lung cancer. Int J Clin Exp Pathol 2015;8:3864-3870.

34 Zhang HD, Sun DW, Mao L, Zhang J, Jiang LH, Li J, Wu Y, Ji H, Chen W, Wang J, Ma R, Cao HX, Wu JZ, Tang JH: MiR-139-5p inhibits the biological function of breast cancer cells by targeting Notch1 and mediates chemosensitivity to docetaxel. Biochem Biophys Res Commun 2015;465:702-713.

35 Sita-Lumsden A, Dart DA, Waxman J, Bevan CL: Circulating microRNAs as potential new biomarkers for prostate cancer. Br J Cancer 2013;108:1925-1930.

36 Roldo C, Missiaglia E, Hagan JP, Falconi M, Capelli P, Bersani S, Calin GA, Volinia S, Liu CG, Scarpa A, Croce CM: MicroRNA expression abnormalities in pancreatic endocrine and acinar tumors are associated with distinctive pathologic features and clinical behavior. J Clin Oncol 2006;24:4677-4684.

37 Eis PS, Tam W, Sun L, Chadburn A, Li Z, Gomez MF, Lund E, Dahlberg JE: Accumulation of miR-155 and BIC RNA in human B cell lymphomas. Proc Natl Acad Sci USA 2005;102:3627-3632.

38 Cortez MA, Bueso-Ramos C, Ferdin J, Lopez-Berestein G, Sood AK, Calin GA: MicroRNAs in body fluids--the mix of hormones and biomarkers. Nat Rev Clin Oncol 2011;8:467-477. 